\title{
SST fronts along the Gulf Stream and Kuroshio affect the winter climatology primarily in the absence of cyclones
}

\author{
Leonidas Tsopouridis $^{1}$, Thomas Spengler ${ }^{1}$, and Clemens Spensberger ${ }^{1}$ \\ ${ }^{1}$ Geophysical Institute, University of Bergen, and Bjerknes Centre for Climate Research, Bergen, Norway \\ Correspondence: leonidas.tsopouridis@uib.no
}

\begin{abstract}
The Gulf Stream and Kuroshio regions feature strong sea surface temperature (SST) gradients that influence cyclone development and the storm track. Smoothing the SSTs in either the North Atlantic or North Pacific has been shown to yield a reduction in cyclone activity, surface heat fluxes, and precipitation, as well as a southward shift of the storm track and the upper-level jet. To what extent these changes are attributable to changes in individual cyclone behaviour, however, remains

5 unclear. Comparing simulations with realistic and smoothed SSTs in the atmospheric general circulation model AFES, we find that the intensification of individual cyclones in the Gulf Stream or Kuroshio region is only marginally affected by reducing the SST gradient. In contrast, we observe considerable changes in the climatological mean state, with a reduced cyclone activity in the North Atlantic and North Pacific storm tracks that are also shifted equator-ward in both basins. The upper-level jet in the Atlantic also shifts equator-ward, while the jet in the Pacific strengthens in its climatological position and extends further east.

Surface heat fluxes, specific humidity, and precipitation also respond strongly to the smoothing of the SST, with a considerable decrease of their mean values on the warm side of the SST front. This decrease is more pronounced in the Gulf Stream than in the Kuroshio region, due to the amplified decrease in SST along the Gulf Stream SST front. Subdividing the winter climatology into dates with/without cyclones present in the Gulf Stream and Kuroshio regions, we find that cyclones play only a secondary role in explaining the mean states differences between the smoothed and realistic SST experiments.
\end{abstract}

\section{Introduction}

The Gulf Stream and Kuroshio region with their strong sea surface temperature (SST) gradients are preferential locations for cyclogenesis (e.g., Hoskins and Hodges, 2002; Nakamura et al., 2004) and are found to determine the location and structure of storm tracks (e.g., Chen et al., 2010; Ogawa et al., 2012; Ma et al., 2015; Yao et al., 2018). Sensitivity tests with smoothed SSTs and a weaker SST gradient yield a reduced cyclone activity. In addition, these experiments feature an equator-ward shift of both the storm track as well as the upper level jet (e.g., Ma et al., 2015; Zhang et al., 2020) and a decrease of surface heat fluxes as well as precipitation on the warm side of the SST front (e.g., Kuwano-Yoshida et al., 2010b; Kuwano-Yoshida and 
Minobe, 2017). However, as it remains unclear if the latter changes can be attributed to the changes in cyclone activity, we quantify the contribution of cyclones to the documented differences in the Gulf Stream and Kuroshio region.

SST gradients also influence individual cyclone intensification (e.g., Sanders, 1986; Wang and Rogers, 2001; Jacobs et al., 2008), where the intensification has been associated to low-level baroclinicity originating from sensible heat fluxes (e.g., Hotta and Nakamura, 2011) and latent heating (e.g., Papritz and Spengler, 2015) along the SST front. However, other studies related the intensification of individual cyclones in the western Atlantic to the low-level baroclinicity associated with the pronounced land-sea contrast (e.g., Brayshaw et al., 2009; Tsopouridis et al., 2020a). Thus, while several studies highlighted the sensitivity of cyclogenesis and the storm track to a smoothing of the SST (e.g., Nakamura et al., 2008; Kuwano-Yoshida and Minobe, 2017; Ma et al., 2017; Zhang et al., 2020), the impact of a weaker SST gradient on the intensification of individual cyclones remains unclear.

Randomly selecting 24 individual cyclones that occurred in the Gulf Stream region, de Vries et al. (2019) highlighted the reduction of surface latent heat fluxes and low-level baroclinicity when smoothing the SST. They, however, emphasised that these changes vary based on the position of each storm relative to the SST front. Similarly, Tsopouridis et al. (2020a) found cyclones following different pathways with respect to the SST front position to be associated with different characteristics. They, however, attributed the structural changes primarily to the absolute SST over which the cyclone is propagating rather than the SST front itself. Along the same lines, Booth et al. (2012) found storm strength to increase in the Gulf Stream region with increased SSTs, even if only a weak SST gradient is present. Given the twofold dependence on both the absolute SST and the strength of the SST front, the sensitivity of cyclone development with respect to either absolute SST or SST fronts needs to be further clarified.

In addition to low-level baroclinicity, upper-level forcing by the jet stream is known to contribute to cyclogenesis (e.g., Sanders and Gyakum, 1980; Uccellini et al., 1984; Sinclair and Revell, 2000; Yoshida and Asuma, 2004) and can influence cyclone intensification (e.g., Evans et al., 1994; Schultz et al., 1998; Riviere and Joly, 2006; Tsopouridis et al., 2020b). At the same time, the very existence of the extratropical jet depends on the cyclones maintaining the storm track (Hoskins and Valdes, 1990; Holton and Hakim, 2012; Papritz and Spengler, 2015). Accordingly, using experiments with realistic and smoothed SSTs, Kuwano-Yoshida and Minobe (2017) argued that the increased cyclone activity over the SST front influences the upper-level jet, causing its meandering over the North Pacific.

In the light of this tight coupling between the jet and the storm track, it is not surprising that a smoothing of the SST can affect the upper-level flow. Indeed both the storm track (e.g., Small et al., 2014; Ma et al., 2015; Piazza et al., 2016; Zhang et al., 2020) and the upper-level jet (e.g., Ma et al., 2017; O'Reilly et al., 2017) were shown to shift equatorward in the North Atlantic and Pacific ocean when the SSTs were smoothed. Kuwano-Yoshida and Minobe (2017) showed that smoother SST in the Kuroshio region resulted in a more zonally oriented storm track and argued that a weaker SST front is not able to anchor the upper-level flow. A southward shift of both the storm track density and the upper-level jet when smoothing the SST has also been documented in the North Atlantic region by Piazza et al. (2016), though their shift of the storm track was smaller compared to the one in the study of Small et al. (2014). They related this difference to the stronger SST smoothing in the study of Small et al. (2014). Based on the aforementioned arguments, a smoothing of an already climatologically weaker SST front 
in the Kuroshio region (e.g., Nakamura et al., 2004; Tsopouridis et al., 2020b) should have a comparatively minor impact on the storm track and the upper-level wind speed compared to the Gulf Stream region.

60 Focusing on mesoscale aspects of the atmospheric response to a smoothing of the SSTs, Piazza et al. (2016) documented a considerable decrease in the surface heat fluxes (30-50\%) and convective precipitation (up to 60\%) over the warm side of the North-Atlantic SST front after they removed small-scale SST features. Consistently, Zhang et al. (2020) found a similar, yet significantly smaller, decrease of the surface heat fluxes (5\%) and precipitation (7\%) within the Kuroshio and Oyashio confluence region. Atmospheric general circulation model (AGCM) experiments with real and smoothed SSTs revealed that

65 the SST front is important to maintain convective precipitation (in line with Minobe et al., 2008), with the atmospheric response of the SST smoothing being stronger in the Gulf Stream than in the Kuroshio region (Kuwano-Yoshida et al., 2010b). Indeed, comparing differences in precipitation between the original and smoothed SSTs as well as between the Atlantic (Minobe et al., 2008) and the Pacific (Kuwano-Yoshida and Minobe, 2017), the decrease of precipitation is more pronounced in the Gulf Stream region. Thus, surface heat fluxes and precipitation are considerably affected by the strength of the SST gradient, with 70 the effect being stronger in the Gulf Stream than in the Kuroshio region. However, whether surface heat fluxes and precipitation are only altered by the SST gradients or to what extent changes in the occurrence of cyclones contribute to their distribution remains ambiguous.

While the ability of extratropical cyclones to strongly modulate the moisture transport (e.g., Ruprecht et al., 2002; Chang and Song, 2006) and precipitation (e.g., Bjerknes, 1922; Pfahl and Wernli, 2012; Hawcroft et al., 2012) is commonly accepted,

75 a similar association between cyclones and heat fluxes is under debate. Some studies suggest a close relationship between the surface heat fluxes and cyclones in the midlatitudes on both synoptic (e.g., Alexander and Scott, 1997; Schemm et al., 2015; Dacre et al., 2020) and longer time scales (e.g., Parfitt et al., 2016; Ogawa and Spengler, 2019). Using a more statistical approach, Zolina and Gulev (2003) argued that the surface fluxes mainly occur on synoptic time scales. However, based on a composite analysis Rudeva and Gulev (2011) actually indicated that cyclones in the North Atlantic do not contribute significantly to the climatological surface heat fluxes in this region. Furthermore, Tanimoto et al. (2003) noted that in regions with active ocean dynamics, such as along the western boundary currents, the SST anomalies mainly regulate the surface heat fluxes and not the cyclones.

To shed light to the outlined uncertainties, we assess the effect of a weak or strong SST gradient using an atmospheric general circulation model (AFES 3) based on simulations with realistic and smoothed SSTs in the Gulf Stream and Kuroshio region. Our analysis of these simulations is twofold. Firstly, we follow the approach of Tsopouridis et al. (2020a, b, hereafter TSSa,TSSb) and investigate the effect of the smoothed SSTs on the structure of individual cyclones. Secondly, we examine the contributions of cyclones on the different winter climatologies between the realistic and smoothed simulations (similar to Ma et al., 2015). This two-pronged approach allows us to establish a link between changes in the structure of individual cyclones and changes in the winter climatology. As we will show, the impact on individual cyclones is markedly smaller compared to changes in the winter climatology, suggesting potential answers to the questions raised above. 


\section{Data and Methods}

\subsection{Data}

We use data from version 3 of the Atmospheric General Circulation Model (AGCM) for the Earth Simulator (AFES) developed by the Earth Simulator Center of the Japan Agency for Marine Earth Science and Technology (Ohfuchi et al., 2004; Enomoto 95 et al., 2008; Kuwano-Yoshida et al., 2010a). This version of AFES has been first used by Kuwano-Yoshida and Minobe (2017) and O'Reilly et al. (2017), and has a horizontal resolution of T239 (approximately $50 \mathrm{~km}$ ) and 48 sigma levels in the vertical. The model was integrated from 1 September 1981 to 31 August 2001, where we only focus on the winter periods December to February, hereafter DJF. In the production of the AFES data, NOAA $0.25^{\circ}$ daily SST data (Reynolds et al., 2007) were used as boundary conditions. More information about the model configuration can be found in Kuwano-Yoshida and Minobe (2017).

100 Kuwano-Yoshida and Minobe (2017), using AFES 3 produced two experiments for the North Pacific. Firstly, the control experiment (hereafter CNTL) that uses the original global SST data and secondly an experiment that uses smoothed SSTs over the Northwestern Pacific (hereafter SMTHK). They also composed an analogous experiment with spatially smoothed SSTs over the Northwestern Atlantic (hereafter SMTHG). In both cases, the NOAA $0.25^{\circ}$ daily SST were smoothed by applying a 1-2-1 running mean filter 200 times in the zonal and meridional direction.

105 We use SST, latent and sensible heat fluxes, large-scale and convective precipitation, specific humidity at $850 \mathrm{hPa}$, and wind at $300 \mathrm{hPa}$ for our analysis. We also compare the model simulations with the same variables from the ERA-Interim reanalysis that was created using a four-dimensional variational data assimilation scheme and a spectral truncation of T255 and 60 levels in the vertical (Dee et al., 2011).

\subsection{SST front and jet stream detection}

110 We identify the position of SST fronts using an objective frontal detection scheme based on the "thermal" method, as described in detail by Tsopouridis et al. (2020a). This method has also been used to detect atmospheric fronts (Jenkner et al., 2010; Berry et al., 2011; Schemm et al., 2015). To capture the most prominent SST fronts, we have chosen a SST gradient threshold of $2 \mathrm{~K} / 100 \mathrm{~km}$ for the Atlantic and a smaller threshold of $1.25 \mathrm{~K} / 100 \mathrm{~km}$ for the Pacific region. The smaller threshold in the Pacific is due to the weaker SST gradient, as documented by Nakamura et al. (2004), and in line with the previous studies of TSSa for 115 the Atlantic and TSSb for the Pacific.

To assess the potential impact of the SST smoothing on the upper levels, we detect the jet stream position in both basins for the three experiments using the method and criteria of Spensberger et al. (2017), which identifies lines separating cyclonic from anticyclonic wind shear yielding automatically detected jet axes. 


\subsection{Cyclone detection and tracking}

We employ the University of Melbourne cyclone detection and tracking algorithm (Murray and Simmonds, 1991a, b). The algorithm detects maxima in the Laplacian of the MSLP field and tracks them over time using a nearest-neighbour method together with the most likely direction of propagation (Murray and Simmonds, 1991a, b; Michel et al., 2018; TSSa; TSSb).

Analogous to TSSa; TSSb, we take into account only cyclones propagating for at least 12 hours (three consecutive timesteps) in the Gulf Stream region $\left(30-50^{\circ} \mathrm{N}\right.$ and $\left.290-310^{\circ} \mathrm{E}\right)$ and the Kuroshio Extension region $\left(30-50^{\circ} \mathrm{N}\right.$ and $\left.145-170^{\circ} \mathrm{E}\right)$. We also require the great circle distance between cyclogenesis and cyclolysis to be greater than $300 \mathrm{~km}$ in order to remove quasi-stationary systems.

\subsection{Classification of cyclone tracks based on their position relative to the SST front}

We categorise the identified cyclone tracks with a maximum intensification in either the Gulf Stream region or the Kuroshio region based on their propagation relative to the SST front. Firstly, we identify the shortest distance between each cyclone position and the SST front for every time-step along the cyclone track and define a vector pointing to the cyclone. Then, we follow TSSa and TSSb and focus on cyclones that always stay on the cold (C1) or warm (C2) side of the SST front, and those that cross the SST front from the warm to the cold side (C3).

We categorise the cyclones for the SMTHG and SMTHK experiments analogously to the CNTL experiment. However, as the SST gradient in the smoothed experiments is too weak to qualify as a front, we instead use the front positions from the CNTL experiment for the classification. We thus categorise cyclone tracks based on similarities in their geographical location and propagation direction to achieve a consistent classification of the cyclone tracks across all AFES experiments. For simplicity we still refer to C1-3 as the cold, warm, and crossing cases for the smooth experiments, even though, strictly speaking, no front is crossed.

\subsection{Decomposition of climatological differences}

140 In addition to the cyclone track classification, we decompose the winter climatology into dates with and without cyclones present the Gulf Stream or the Kuroshio region, respectively. This decomposition allows us to assess how much of the climatological differences in the smoothed experiment arise while cyclones are present in the respective region, and thus how much of the climatological differences are directly or indirectly associated with cyclones. For this analysis, we consider all cyclones that pass through either the Gulf Stream or the Kuroshio region during their evolution, irrespective of their direction of propagation and the location of their maximum intensification. 

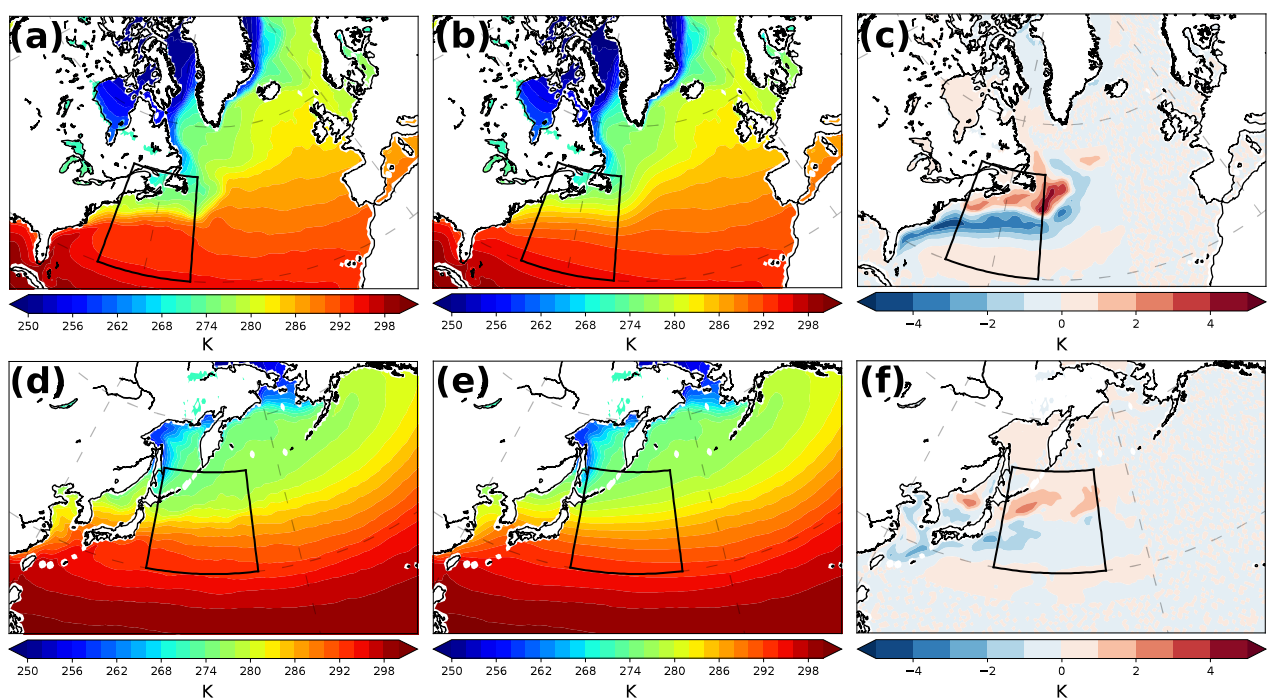

Figure 1. (a) Climatological SSTs in DJF for (a) CNTL, (b) SMTHG, and (c) the difference between SMTHG and CNTL (K). (d-f) as (a-c), but for the North Pacific.

\section{Results and Discussion}

\subsection{SST front and SST/SST gradient distribution between the experiments}

Analysing the SST (Fig. 1a) and SST gradient (Fig. 2a) distribution in the Gulf Stream region for CNTL, we note a remarkable SST contrast across the Gulf Stream, which results in a strong SST gradient (Fig. 2a) and in locally well-confined SST front detections (Fig. 3a), consistent with an oceanographic viewpoint (Meinen and Luther, 2016). The SST front distribution also resembles the correspondent feature presented in TSSa for the same region, but based on a different period and dataset.

Across the Kuroshio, we observe an overall similar, but less spatially confined, SST contrast compared to the Gulf Stream region (compare Fig. 1a with Fig. 1d), which results in a weaker SST gradient in the Kuroshio region (Fig. 2d). Consequently, the detected SST fronts are more wide-spreadly distributed in the Pacific (Fig. 3b), but remain collocated with the region of the climatologically largest SST gradient (in line with, e.g., Tozuka et al., 2018; Wang et al., 2019). The less pronounced SST gradient in the Pacific compared to the Atlantic is also evident in the ERA-Interim winter climatology (Fig. A1b,e), with the differences between the reanalysis and AFES simulations arising from the coarser SST resolution used in ERA-Interim prior to 2002 (e.g., Masunaga et al., 2015; Parfitt et al., 2017).

Compared to CNTL, the SSTs in SMTHG are smoother and their gradient is more widely distributed (compare Fig. 1a and

Fig. 1b). In the western Atlantic, we also observe that the smoothing affects SSTs at a considerable distance from the Gulf 

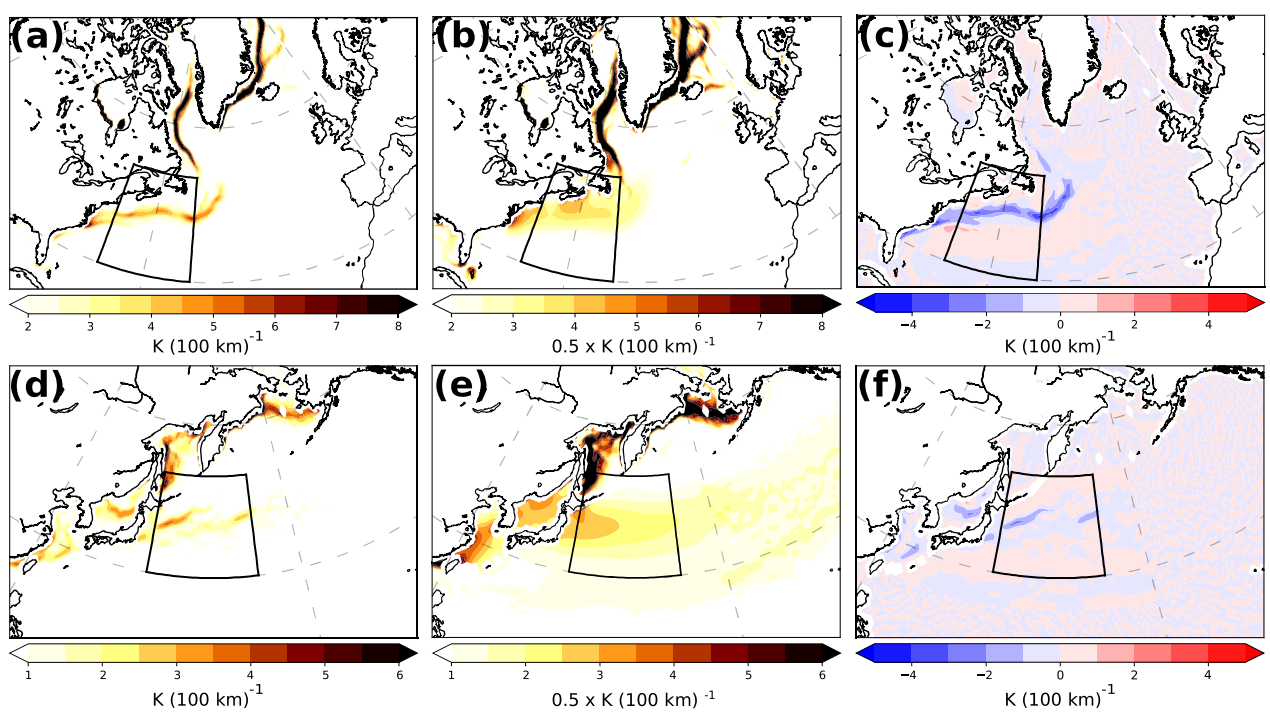

Figure 2. (a) Climatological SST gradient in DJF for (a) CNTL $\left[\mathrm{K}(100 \mathrm{~km})^{-1}\right]$, (b) SMTHG $\left[0.5 \mathrm{~K}(100 \mathrm{~km})^{-1}\right]$, and (c) the difference between SMTHG and CNTL [K $\left.(100 \mathrm{~km})^{-1}\right]$. (d-f) as (a-c), but for the North Pacific.
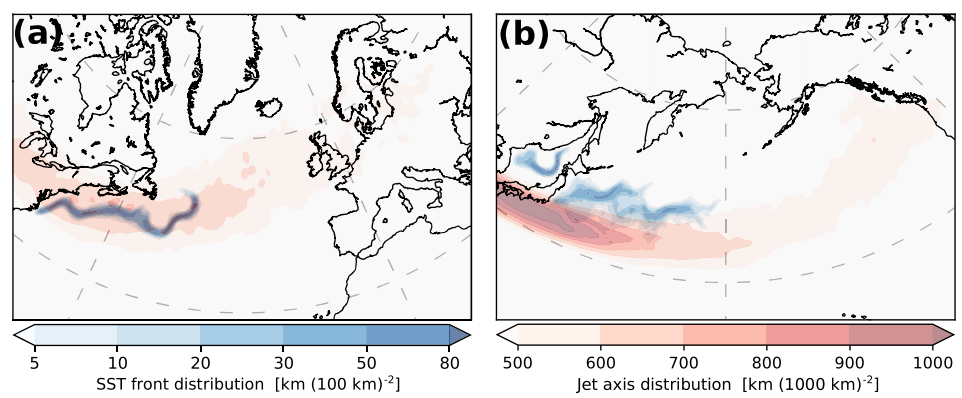

Figure 3. (a) SST front distributions (blue shading, $\mathrm{km}$ of line $\left.(100 \mathrm{~km})^{-2}\right)$ and jet axis distributions (orange shading, $\mathrm{km}$ of jet axis line $\left.(1000 \mathrm{~km})^{-2}\right)$ for the North Atlantic. (b) as (a), but for the North Pacific

Stream SST front (Fig. 3a), for example reducing the SST to the east of the Florida Peninsula (Fig. 1a,b). At approximately $40^{\circ} \mathrm{N}$, the SST differences exhibit a clear dipole, with increased SST to the north and decreased SST to the south, following the position of the SST front (Fig. 1c, Fig. 3a). The largest differences occur offshore off the central US East coast $(\Delta \mathrm{SST}<-4 K)$ as well as off the coast of Newfoundland $(\triangle \mathrm{SST}>4 K$; Fig. 1c). 
The SST distribution in SMTHK (Fig. 1e) is similar to CNTL, though smoother, and the region with the strongest gradients off the east coast of Japan is oriented slightly more zonally (Fig. 1d). Contrary to the Gulf Stream region, the SSTs outside the Kuroshio region remain largely unaffected. As in the Gulf Stream region, the SST differences between the two experiments follow a bipolar structure (Fig. 1f), but they are considerably weaker. The smoothing results in a maximum decrease (increase) of $2 \mathrm{~K}(3 \mathrm{~K})$ south (north) of the SST front (Fig. 1f), with the SST differences being more pronounced in the western part of the domain close to Japan (Fig. 1f).

\subsection{Cyclone Density and Upper-level Wind}

To evaluate the potential impact of the upper-level forcing on cyclones, we present the climatological position of the jet stream over the two ocean basins. The position of the North Atlantic jet coincides with the location of the SST front (Fig. 3a), whereas the Pacific jet is located south of the Kuroshio SST front (Fig. 3b). The Pacific jet is stronger, meridionally more confined, and located over lower latitudes compared to the Atlantic jet, which is consistent with previous studies (e.g., Nakamura, 1992; Spensberger and Spengler, 2020). Both the strength and the position of the jet axes distribution in the North Atlantic are analogous to the study of TSSa, while for the Pacific we observe fewer jets in the region to the south of Japan compared to TSSb.

The changes in the SST field between CNTL and SMTHG/SMTHK introduce differences in both cyclone density and the climatological jet stream position. We observe an equatorward shift in the maximum cyclone density in both the North Atlantic and North Pacific, particularly in the central and eastern part of the basins (Fig. 4a,c). We also notice an analogous shift in the upper-level jet in the North Atlantic (Fig. 4b), with negative anomalies in the northern part of the basin and positive anomalies mainly to the east of the Gulf Stream region. However, a similar shift of the upper-level jet is not observed in the North Pacific, where the position of the jet remains rather unchanged, with a more confined and zonal distribution of the jet in SMTHK (Fig. 4d). We relate the lack of a shift in the upper-level jet in the North Pacific to the small SST difference after the SST smoothing $(\triangle \mathrm{SST}=1 K$; Fig. 1f), whereas in the Atlantic the jet is located near the region with the most pronounced SST changes $(\Delta \mathrm{SST}>4 K$; Fig. $1 \mathrm{c})$.

Analogously, the sharper SST gradient in the Gulf Stream region (Fig. 2c,f) leads to larger changes in storm track activity in the Northwestern Atlantic, with a more pronounced decrease in cyclone density in the Gulf Stream region compared to the Kuroshio region (Fig. 4a,c). This is consistent with Kuwano-Yoshida et al. (2010b) and in line with Nakamura et al. (2008), who found the storm track activity in the Southern Ocean to be substantially weaker after the removal of the strong SST front.

Thus, while differences in cyclone density (Fig. 4a) and jet occurrence (Fig. 4b) are generally collocated in the Atlantic, they are displaced from each other in the Pacific region (Fig. 4c,d), where a considerable increase in cyclone density in the Northeast Pacific (Gulf of Alaska, Fig. 4c) is contrasted by a decrease in the upper-level wind speed (Fig. 4d). Zhang et al. (2020) found a similar decrease in the upper-level response in the northeastern Pacific, expressed by differences of meridional eddy wind variance and eddy kinetic energy at $300 \mathrm{hPa}$. However, they showed that the upper-level decrease was not accompanied by a reciprocal negative anomaly in the low-level storm track and thus documented a different response of the SST smoothing in the lower and upper levels in the Pacific. 

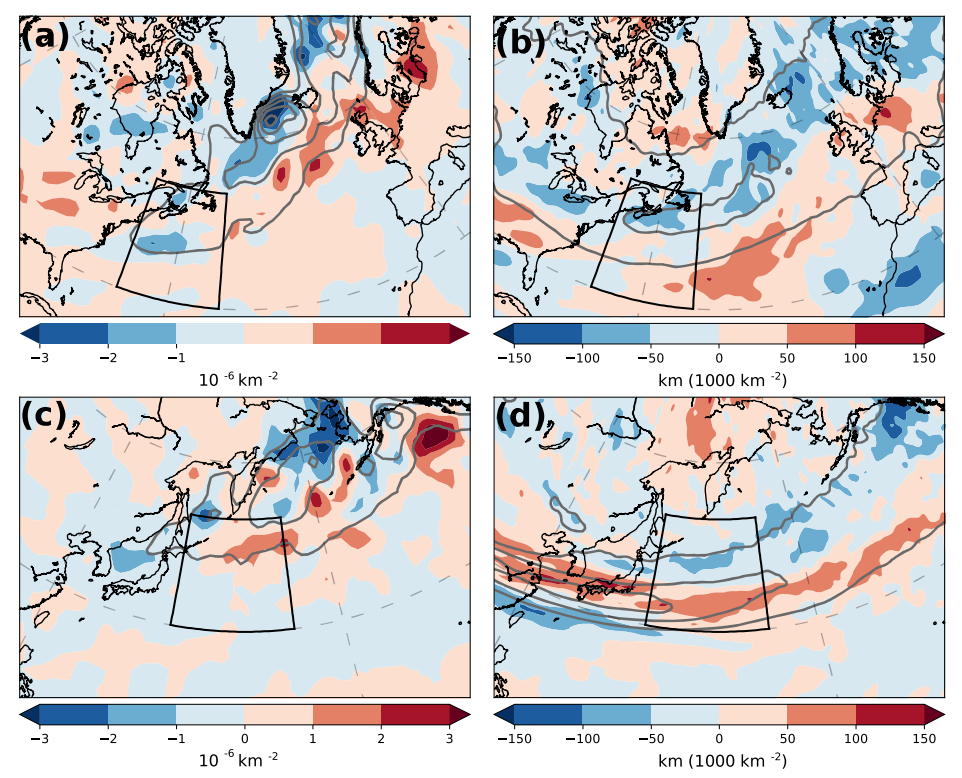

Figure 4. (a) Difference in the climatological cyclone density between SMTHG and CNTL (shading, $10^{-6} \mathrm{~km}^{-2}$ ) and cyclone density (contours, first contour: $6^{*} 10^{-6} \mathrm{~km}^{-2}$, interval $3^{*} 10^{-6} \mathrm{~km}^{-2}$ ) for the CNTL experiment (b) difference in the climatological jet stream (shading, $\mathrm{km}$ of jet axis line $(1000 \mathrm{~km})^{-2}$ ) and jet stream density (contours, first contour: $400 \mathrm{~km}$ of jet axis line $(1000 \mathrm{~km})^{-2}$, interval: 200 $\mathrm{km}$ of jet axis line $(1000 \mathrm{~km})^{-2}$. (c,d) As (a,b), but for the Kuroshio region. The Gulf Stream and Kuroshio regions are marked with a black box, respectively.

\subsection{Categorisation and Intensification of Cyclones}

To assess the effect of smoothing the SSTs on the evolution of individual cyclones, we now restrict our focus to cyclones with maximum intensification in the Gulf Stream or Kuroshio region (details in section 2.4). For the Atlantic CNTL, 57 cyclones consistently stay on the cold side of the Gulf Stream SST front (C1), 27 cyclones stay on the warm side (C2), and 40 cyclones cross the SST front from the warm to the cold side (C3). In SMTHG, 62, 30, and 25 cyclones belong to C1, C2, and C3, respectively. Comparing these numbers, we notice that the number of cyclones staying on either side of the SST front is nearly unaffected by the smoothing, whereas the number of crossing cyclones is substantially reduced. This implies an overall reduction in the number of cyclones, which is in line with the decreased cyclone density along the Gulf Stream SST front in SMTHG (Fig. 3a, Fig. 4a).

In the Kuroshio region, the number of cyclones in C1 (86/81) and C3 (59/60) is more or less unchanged between CNTL/SMTHK, whereas cyclones in C2 (24/14) decrease slightly in number. The restricted number of cyclones in C2, particularly in SMTHK, 

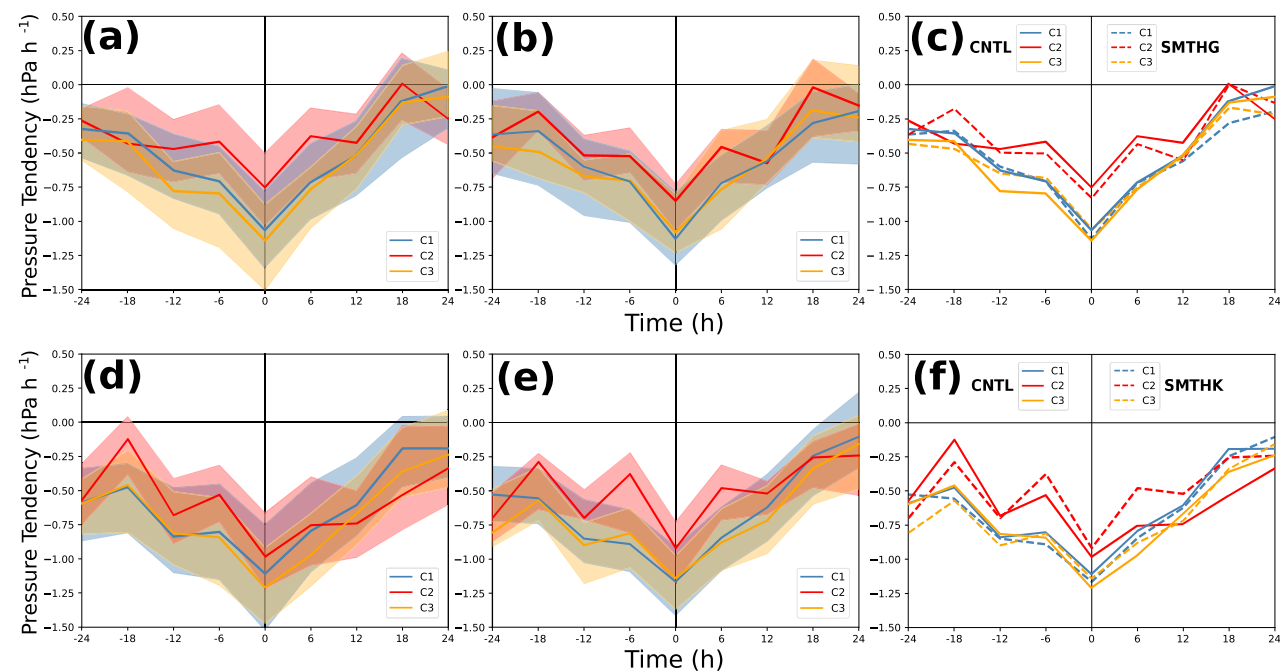

Figure 5. Pressure tendency $\left(\mathrm{hPa} \mathrm{h}^{-1}\right.$ ) for the three categories relative to the time of maximum intensification for (a) CNTL and (b) SMTHG. Lines indicate the median and the shading the interquartile range. (c) Medians of the pressure tendency $\left(\mathrm{hPa} \mathrm{h}^{-1}\right)$ for the three categories relative to the time of maximum intensification for CNTL (solid lines) and SMTHG (dashed lines). (d-f) As (a-c), but for the North Pacific.

implies some uncertainty for the corresponding results. Note that in contrast to the Atlantic, there is no reduction in cyclones crossing the SST front, potentially because the SST gradient in the Pacific is already comparatively weak in CNTL (compare Figs. 2a, d).

The more pronounced reduction of cyclones crossing the SST front in SMTHG compared to SMTHK highlights the significance of a strong SST gradient to anchor the position of the storm track, as discussed in previous studies (e.g., Nakamura et al., 2004, 2008; Sampe et al., 2010). Our results confirm these studies not only based on the number of cyclones, but also based on the location of cyclones during their maximum intensification. In CNTL, most cyclones undergo their most rapid intensification close to the SST front (Fig. A3b), whereas the location of most rapid intensification is distributed over a wider region in SMTHG (Fig. A3e).

Among the three categories, Atlantic cyclones of $\mathrm{C} 3$ and $\mathrm{C} 1$ are deepening the most in CNTL, with a maximum 6-hourly intensification corresponding to approximately 28 and $25 \mathrm{hPa} /$ day, respectively. Conversely, cyclones of $\mathrm{C} 2$ are characterised by a weaker intensification throughout their evolution (Fig. 5a). In SMTHG, cyclones intensify similarly fast as in CNTL (Fig. 5a,b). In particular, cyclones of C3 experience only a slightly weaker intensification in SMTHG, although the SST front that they cross is barely existing in SMTHG. These results support the findings of TSSa, who related the intensification of cyclones in the Gulf Stream region to the low-level baroclinicity associated with the land-sea contrast, hypothesising that a strong SST 

less clear in SMTHG, where the interquartile ranges of the three categories overlap considerably.

In the Kuroshio region, cyclones of $\mathrm{C} 3$ are on average deepening the fastest (approx. $30 \mathrm{hPa} /$ day), followed by cyclones of $\mathrm{C} 1$ (approx. $25 \mathrm{hPa}$ /day; Fig. 5d). In line with TSSb, $\mathrm{C} 2$ becomes the category with the larger deepening rate among the three categories after the time of maximum intensification. In contrast to TSSb, cyclones of $\mathrm{C} 2$, however, deepen the least before their maximum intensification in both CNTL and SMTHK (Fig. 5d,e). We relate this difference to cyclones in the AFES simulations being located further away from an upper-level jet stream than in the ERA-Interim data used in TSSb (not shown), where the upper levels proved to substantially influence the intensification of cyclones in the Kuroshio region. Moreover, the limited number of cyclones in the AFES simulations (24 cyclones in CNTL compared with 97 cyclones in TSSb) lowers the statistical robustness of these results.

In SMTHK, the cyclones in the three categories have similar pressure tendencies as in CNTL (Fig. 5e), which becomes even more apparent when comparing the median of their pressure tendencies (Fig. 5f). In particular, C3 on average intensifies virtually identically in the two experiments. In the light of the corresponding findings for the Gulf Stream region, this result is not surprising. Even for the more focused Gulf Stream SST front, the smoothing had only a minor impact on the evolution of $\mathrm{C} 3$ cyclones (Fig. 2c,f). A more pronounced effect is evident for $\mathrm{C} 2$ cyclones in the Kuroshio region, with cyclones intensifying slightly less after the smoothing. However, the number of cyclones is even smaller in SMTHK (14 cyclones) than in CNTL, making it difficult to draw conclusions from this difference.

Considering the evolution of the SST underneath the cyclone core, cyclones of C1 propagate over comparatively low SSTs, because they remain on the cold side of the SST front in both regions (Fig. 6a,d). In contrast, cyclones of C2 propagate over approximately $16 \mathrm{~K}$ higher SSTs than cyclones of $\mathrm{C} 1$ in the North Atlantic (Fig. 6a) and over 12K higher SSTs in the Pacific (Fig. 6d) during maximum intensification. However, during their evolution, cyclones gradually propagate towards lower SSTs. Cyclones of C3 propagate over higher SSTs at an early stage of their development and over lower SSTs after crossing the SST front. The latter is associated with the cross-frontal SST difference, which is more pronounced in the Atlantic (Fig. 6a) than in the Pacific (Fig. 6d) due to the sharper Gulf Stream SST front (consistent with Nakamura et al., 2004; Joyce et al., 2009; TSSb).

After the SST smoothing, cyclones of C1 propagate over approximately $1 \mathrm{~K}$ higher SSTs in both regions and cyclones of C2 over 1-2 K lower SSTs. Further, cyclones of C3 in the smoothed experiments experience a less sharp decrease in SST across the SST front compared to the CNTL experiment (Fig. 6b,c,e,f). The SST differences introduced by the smoothing are more pronounced before maximum intensification, because at this stage cyclones typically propagate in the western part of the regions of interest where the SST differences associated with the smoothing tend to be larger (Fig. 1c,f).

Overall, the considerable reduction in the number of cyclones of C3 after the smoothing of the SST in the Atlantic highlights the anchoring effect of a strong Gulf Stream SST front on the storm track. On the other hand, the already weak SST gradient in the Kuroshio prior to the smoothing leads to minor SST differences between CNTL and SMTHK and thus to a similar number of cyclones that cross the SST front. The rather similar cyclone intensification between the experiments indicate that the SST gradient is not particularly important for the intensification of individual cyclones (consistent with TSSa; TSSb). 

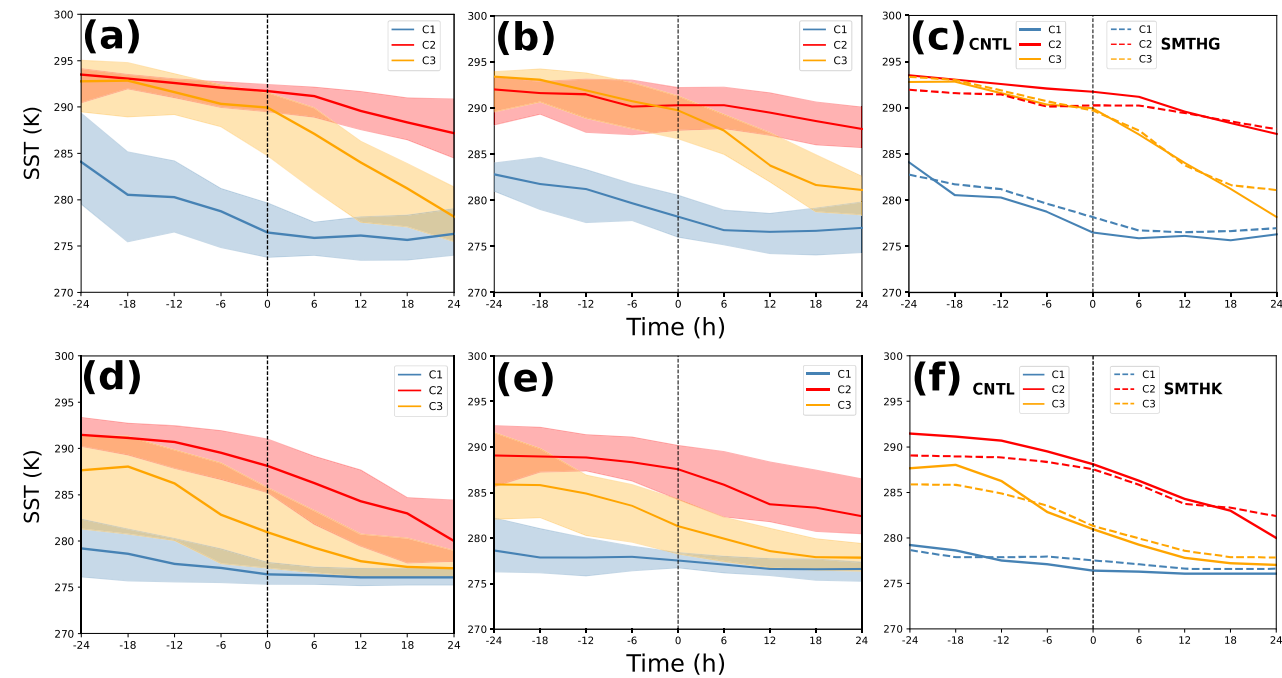

Figure 6. SSTs (K) for the three categories relative to the time of maximum intensification for (a) CNTL and (b) SMTHG. Lines indicate the median and the shading the interquartile range. (c) Medians of the SSTs (K) for the three categories relative to the time of maximum intensification for CNTL (solid lines) and SMTHG (dashed lines). (d-f) As (a-c), but for the North Pacific.

Our results thus suggest that the SST smoothing does not result in significant differences in the characteristics of individual cyclones. This result is supported by cyclone-relative composites of, for example, surface heat fluxes and precipitation, which exhibit only minor differences between the smooth and CNTL experiments for all cyclone categories (not shown). Nevertheless, we observe a latitudinal shift in the storm track and the jet stream climatologies associated with the SST smoothing (Fig. 4) and previous studies documented a significant reduction in the climatological surface heat fluxes and precipitation (e.g., KuwanoYoshida et al., 2010b; Kuwano-Yoshida and Minobe, 2017). This discrepancy raises the questions how the largely unaffected characteristics of individual cyclones relate to the evident changes in the climatological mean state of the storm track. In the following, we turn to this question by decomposing the winter climatology into dates with and without cyclones propagating through either the Gulf Stream or Kuroshio region.

\subsection{Contribution of cyclones to the climatological differences introduced by smoothing the SST}

\subsubsection{Surface Heat Fluxes}

In the CNTL climatology, we observe a maximum of latent and sensible surface heat fluxes on the warm side of both the Gulf Stream and the Kuroshio SST front (Fig. 7a,e). Peak latent heat fluxes are slightly offset to the south of the peak sensible heat fluxes. TSSb associated this offset with the increase of sea surface saturation mixing ratio with increasing SSTs, following 
the Clausius-Clapeyron relation. In the North Atlantic, latent and sensible heat fluxes exceed $350 \mathrm{~W} \mathrm{~m}^{-2}$ and $80 \mathrm{~W} \mathrm{~m}^{-2}$, respectively (Fig. 7a). Sensible heat fluxes are slightly larger in the North Pacific, whereas latent heat fluxes remain slightly weaker (Fig. 7e).

The surface heat fluxes are similarly distributed in the ERA-Interim dataset, though latent heat fluxes in CNTL are considerably larger compared to ERA-Interim (compare Fig. 7a with Fig. A1c, and Fig. 7e with Fig. A1f). This discrepancy most likely arises from the difference of the SST resolution between the AFES and ERA-Interim, with the latter having a lower resolution prior to 2002. Comparing the CNTL fluxes with the ERA-Interim winter climatology after 2002, the differences are significantly reduced (not shown).

The SST smoothing affects the amount of surface heat fluxes in both regions, though to a different extent. In the Gulf Stream region, we observe considerably weaker surface heat fluxes (Fig. 7b) along the weaker SST gradient (Fig. 2c). The maximum decrease of the latent heat fluxes is of the order of $120 \mathrm{~W} \mathrm{~m}^{-2}$, while the reduction of sensible heat fluxes exceeds $30 \mathrm{~W}$ $\mathrm{m}^{-2}$ (in line with Small et al. (2014)). A slight increase of surface heat fluxes is observed mainly to the northeast and less in the southern parts of the Gulf Stream region (Fig. 7b), consistent with the increase of SSTs due to the smoothing (Fig. 1c). This dipole of positive and negative anomalies of the surface heat fluxes is less pronounced in the Kuroshio region (Fig. 7f), reaching only about half the amplitude compared to the Gulf Stream region. We attribute the reduced amplitude to the smaller impact of the SST smoothing on the SST distribution in the Kuroshio region (Fig. 1f).

290 To estimate the role of cyclones being present for the differences when smoothing the SST, we subdivide the differences between SMTHG/SMTHK and CNTL into time-steps with or without cyclones in the Gulf Stream or Kuroshio region, respectively (Fig. 7c,d,g,h). In the Gulf Stream region, cyclones are present about a third of the time-steps in both CNTL and SMTHG. In the Kuroshio region, cyclones are slightly more prevalent, and a cyclone is present in about $40 \%$ of the time-steps.

The division into cyclone/no-cyclone time-steps shows that the climatological differences between CNTL and SMTHG/SMTHK predominantly arise when no cyclones are present in the respective region (Fig. 7c,d,g,h). The contribution from no-cyclone time-steps is larger in amplitude and the distribution of the flux anomalies more closely resembles the climatological differences between the experiments (Fig. 7b,f). The largest differences in Fig. 7d arise close to the climatological SST front position and are clearly connected to the presence or absence of a sharp SST front. This can be explained by a cold air mass transitioning over a SST front experiencing less surface heating when the smoothing reduced the SSTs on the warm side of the SST front in SMTHG and SMTHK (see Fig. 1c,f; Zolina and Gulev, 2003 and Vanniere et al., 2017). The differences are more pronounced in the Gulf Stream region (Fig. 7c,d) compared to Kuroshio (Fig. 7g,h) due to the larger total mean differences of surface heat fluxes after the SST smoothing in the Atlantic (Fig. 7b,f).

Our results indicate that the smoothing of the SST front has only a minor effect when cyclones are present, which is confirmed by a cyclone-relative composite analysis, where surface heat fluxes are only moderately reduced by the smoothing of the SST front (not shown). Our findings are also in line with Rudeva and Gulev (2011), who indicated that cyclones in the North Atlantic sector do not contribute significantly to the climatological surface heat fluxes in the region. 

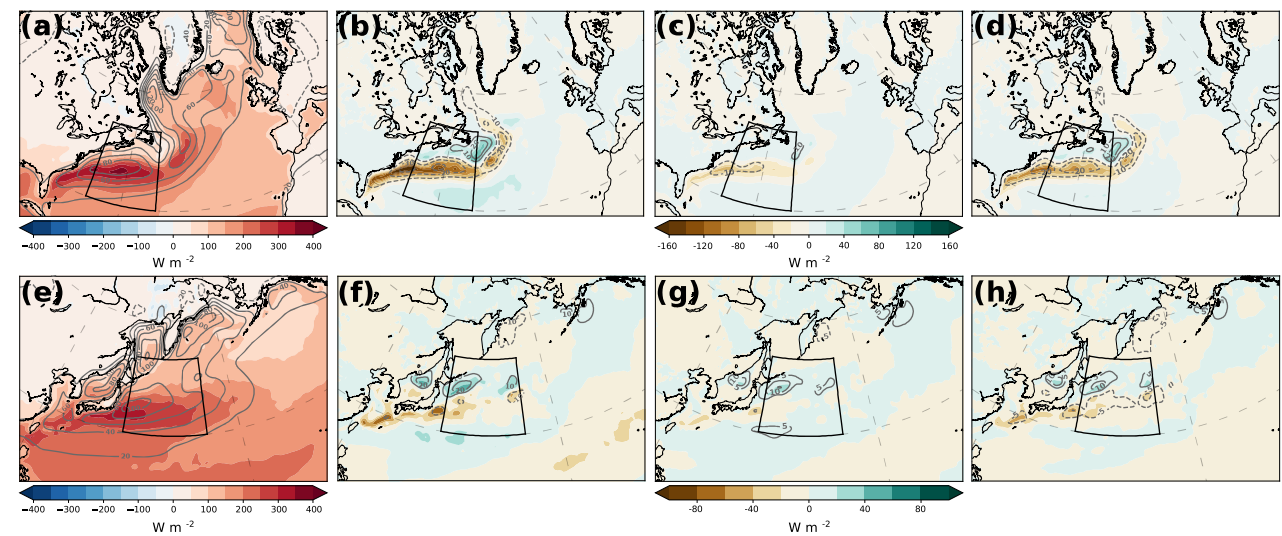

Figure 7. (a) Climatological latent (shading, $\mathrm{W} \mathrm{m}^{-2}$ ) and sensible heat fluxes (contours, $\mathrm{W} \mathrm{m}^{-2}$ ) for the North Atlantic for CNTL. (b) Difference of the heat fluxes climatologies between SMTHG and CNTL for latent (shading) and sensible heat fluxes (grey contours, interval: $10 \mathrm{~W} \mathrm{~m}^{-2}$, zero contour omitted). (c,d) As (b), but only considering the dates with (c) or without (d) cyclones present in the Gulf Stream region. (e-h) As (a-d), but for the Kuroshio region. The Gulf Stream and Kuroshio regions are marked with a black box, respectively. Panels $(\mathrm{c}, \mathrm{d}, \mathrm{g}, \mathrm{h})$ are scaled such that their sum yields panels (b) and (f), respectively.

\subsubsection{Precipitation}

The precipitation distribution in the Atlantic in CNTL is characterised by a maximum of large-scale $\left(>6 \mathrm{~mm} \mathrm{day}^{-1}\right)$ and convective precipitation $\left(>4 \mathrm{~mm}_{\text {day }}{ }^{-1}\right.$ ) along the Gulf Stream SST front extending eastward (Fig. 8a). The maximum values of precipitation are located along the SST front (Fig. 3a), with a well-defined convective rain-band displaced towards the warm side of the Gulf Stream SST front, consistent with the findings of Kuwano-Yoshida et al. (2010b).

In the Pacific, we observe an analogous spatial distribution of the precipitation pattern, but the amplitude is somewhat larger than in the Gulf Stream region (compare Fig. 8a with Fig. 8e). Further, the peaks of large-scale and convective precipitation are more collocated in the Kuroshio region, likely related to the weaker SST gradient (Fig. 2a,d). When compared to ERAInterim (Fig. A2a,d), there is a good resemblance of the spatial distribution of precipitation, but we notice higher large-scale and convective precipitation in AFES, consistent with the larger latent heat flux.

Analogous to the surface heat fluxes, the smoothing of the SSTs affects precipitation in both regions. In the North Atlantic, the smoothing leads to a remarkable decrease of precipitation (Fig. 8b), in line with the study of Kuwano-Yoshida et al. (2010b). In the North Pacific, however, precipitation is reduced considerably less, with both large-scale and convective precipitation being reduced by less than $1 \mathrm{~mm}$ day $^{-1}$ (consistent with Zhang et al. (2020)). We relate the more pronounced reduction of precipitation in the Gulf Stream to the originally sharper SST gradient (Fig. 2). We also observe a similar dipole pattern with reduced precipitation over the Gulf stream and Kuroshio core as well as increased precipitation in the southeast of both regions 

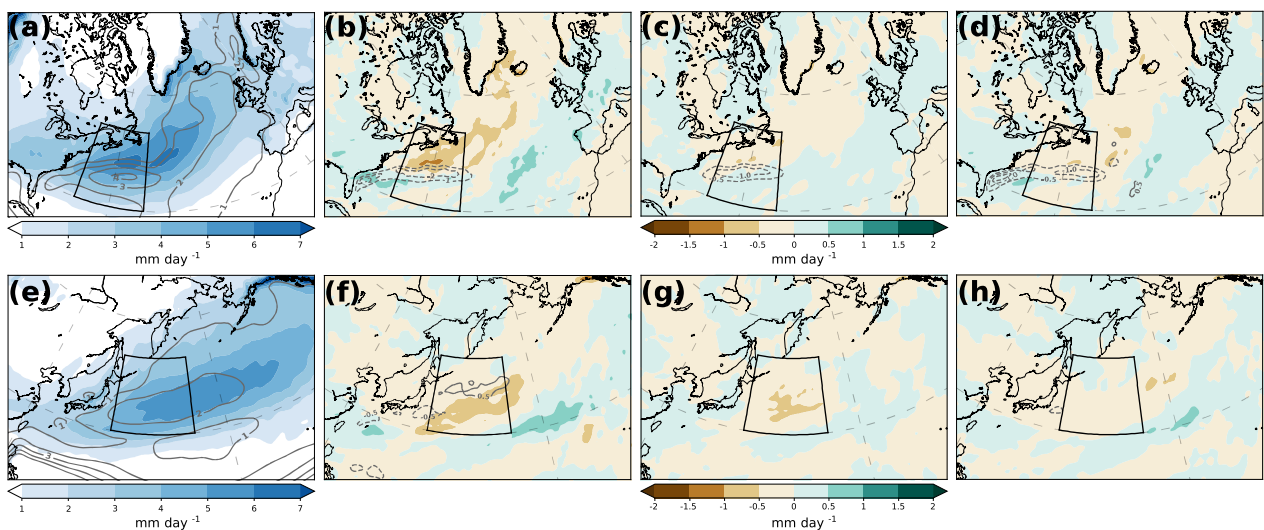

Figure 8. (a) Climatological large-scale precipitation (shading, $\mathrm{mm} \mathrm{day}^{-1}$ ) and convective precipitation (grey contours, interval: 1 , mm day $^{-1}$, zero contour omitted) for the North Atlantic for CNTL. (b) Difference of the precipitation climatologies between SMTHG and CNTL for the large-scale (shading) and convective precipitation (grey contours, interval: $1, \mathrm{~mm} \mathrm{day}^{-1}$, zero contour omitted). (c,d) As (b), but only considering the dates with (c) or without (d) cyclones present in the Gulf Stream region. (e-h) As (a-d), but for the Kuroshio region. The Gulf Stream and Kuroshio regions are marked with a black box, respectively. Panels (c,d,g,h) are scaled such that their sum yields panels (b) and (f), respectively.

(Fig. 8b,f). This equatorward shift in precipitation is consistent with the equatorward shift of the storm track in the smoothed experiments (Fig. 4).

Among the two types of precipitation, convective precipitation is more sensitive to the SST smoothing. In SMTHG, the mean convective precipitation is reduced by half compared to CNTL and the narrow convective precipitation band observed in CNTL largely disappears in SMTHG (not shown). This finding is in line with Minobe et al. (2008) and Kuwano-Yoshida et al. (2010b), who showed that the Gulf Stream SST front is crucial for the distribution and amount of convective precipitation and found convective precipitation to be significantly reduced after heavily smoothing the SST distribution in their simulations with the same model.

Compared to the surface heat fluxes, the precipitation associated with cyclones is more influenced by the SST smoothing. There is a noticeable reduction in convective precipitation in the Gulf Stream region just south of the climatological position of the SST front (Fig. 8c), the region featuring the strongest decrease of SST due to the smoothing (Fig. 1c). This finding supports TSSa, who found convective precipitation to be closely related to the SSTs underneath the cyclone core. When no cyclone is present in the Gulf Stream region, the SST smoothing results in a reduction of both large-scale and convective precipitation almost everywhere in the Gulf Stream region.

Overall, cyclones account for a larger fraction of the precipitation differences than they did for the difference in surface heat fluxes when comparing CNTL and SMTHG. This result is in line with Hawcroft et al. (2012), who found the winter 
precipitation in the Northern Hemisphere to be associated with extratropical cyclones. They also showed that the contribution that precipitation should significantly shift equatorward along with the cyclone track density, which is consistent with our analysis (Figs. 4a, 8c).

In the Kuroshio region we note a rather equal influence of the SST smoothing on precipitation when cyclones are present or absent. These differences mainly concern the large-scale precipitation and are more evident to the east of the Kuroshio region in the no-cyclone case (Fig. 8h), forming a dipole of reduced precipitation to the north and increased precipitation to the south, similar to the Atlantic (Fig. 8d). Interestingly, we note a slightly higher decrease of large-scale precipitation (approx. 0.25 $\mathrm{mm}$ day $^{-1}$ ) when cyclones are present in the Kuroshio region, which is most likely related to a diminished cyclone density in SMTHK compared to CNTL (Fig. 4c).

\subsubsection{Specific Humidity at $850 \mathrm{hPa}$}

Higher values of specific humidity are observed to the south of the Gulf Stream and Kuroshio region (Fig. 9a,e) due to the Clausius-Clapeyron relation with higher SSTs (Fig. 1a,d). The specific humidity maximum exceeds $6 \mathrm{~g} \mathrm{~kg}^{-1}$ in the Gulf Stream region, while lower maximum values $\left(5 \mathrm{~g} \mathrm{~kg}^{-1}\right)$ are found in the southeastern part of the Kuroshio region (Fig. 9a,e). The values are comparable to ERA-Interim (Fig. A2b,e).

Analogous to the surface heat fluxes (Fig. 7b,f), smoothing the SST causes a noticeable decrease in specific humidity to the south of the SST front (Fig. 9b,f), where the SSTs are lower than in CNTL (Fig. 1c,f). The decrease in specific humidity is more pronounced in the Gulf Stream region, following the larger SST decrease in the Atlantic when the SSTs are smoothed. Our findings are consistent with the results of Zhang et al. (2020), who analysed the meridional eddy specific humidity flux instead of specific humidity.

For specific humidity, cyclones account only for a small part of the climatological differences between CNTL and SMTHG (Fig. 9c,d). In addition to the larger amplitudes of the differences when no cyclones are present in the Gulf Stream, also the structure is slightly different, with the negative anomalies being more zonally oriented than when cyclones propagate in the region. In the presence of cyclones, specific humidity is generally reduced in SMTHG (Fig. 9c). In contrast, in the absence of cyclones, a slight increase in specific humidity is evident to the north of the SST front, where the smoothing leads to an SST increase (Fig. 9d). The largest differences in Fig. 9d arise towards the warm flank of the climatological SST front and are clearly related to the largest decrease in the SST between SMTHG and CNTL (Fig. 1c). The more pronounced decrease of specific humidity in the absence of cyclones in the Gulf Stream region resembles the decrease in surface heat fluxes (Fig. $7 \mathrm{c}, \mathrm{d})$, which was also larger in the absence of cyclones.

In the Kuroshio region, the difference in specific humidity (Fig. 9f) is distributed more equally between time-steps with and without cyclones present (Fig. 9g,h). Indeed, cyclones even contribute more to the reduction in specific humidity in the southern of the Kuroshio region (Fig. 9g) than no-cyclone time-steps (Fig. 9h). The reduction in specific humidity likely explains the reduction of large-scale precipitation in the same location (Fig. 8g,h). Nonetheless, in absolute terms these differences remain small. 

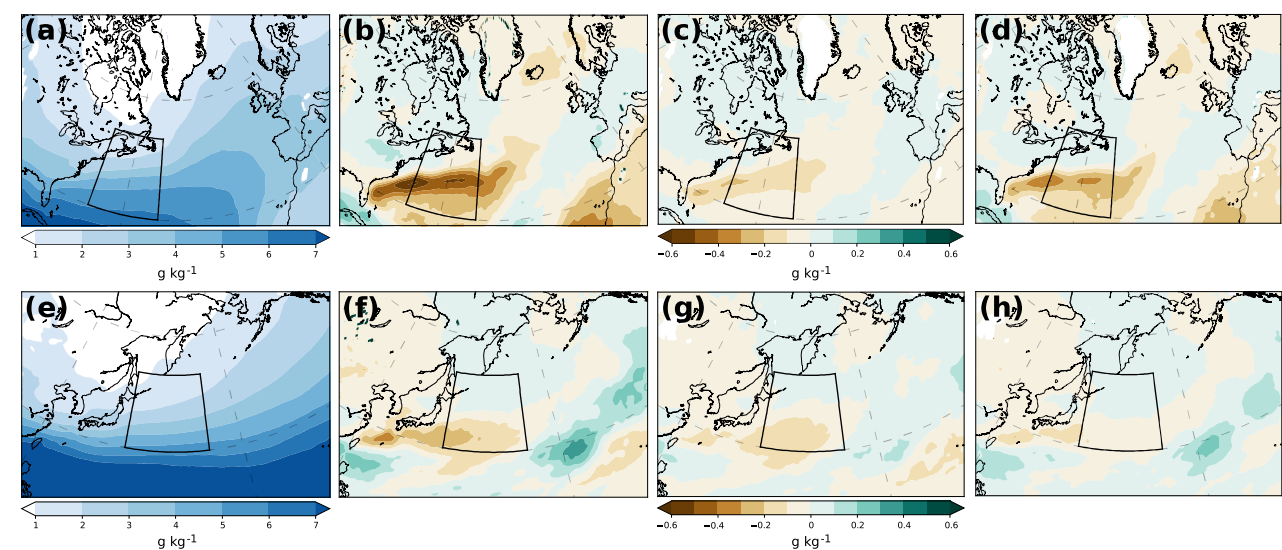

Figure 9. (a) Climatological specific humidity at $850 \mathrm{hPa}$ (shading, $\mathrm{g} \mathrm{kg}^{-1}$ ) for the North Atlantic for CNTL. (b) Difference of climatological specific humidity between SMTHG and CNTL. (c,d) As (b), but only considering the dates with (c) or without (d) cyclones being present in the Gulf Stream region. (e-h) As (a-d), but for the Kuroshio region. The Gulf Stream and Kuroshio regions are marked with a black box, respectively. Panels (c,d,g,h) are scaled such that their sum yields panels (b) and (f), respectively.

We hypothesise that the different distribution of specific humidity between the dates with and without cyclones in the two regions arises from the different ratios of cyclones being present or absent in the Gulf Stream and the Kuroshio region, respectively. Cyclones are present in the Gulf Stream region in about 30\% of the time-steps, whereas the respective percentage is higher in the Kuroshio region (about \% 40 of the time-steps). Therefore, the less pronounced decrease in humidity in the cyclone days in the Atlantic is most likely related to the smaller amount of time-steps, whereas the more equal split in decrease of specific humidity in the Pacific is attributable to the more equal split into cyclone/no-cyclone days.

Apart from the well-established Clausius-Clapeyron relationship between SSTs and moisture, several studies indicate the leading role of cyclones on the poleward transport of moisture (e.g., Peixoto and Oort, 1992; Nakamura et al., 2004; Chang and Song, 2006; Newman et al., 2012). However, based on the subdivision of the winter climatology into cyclone/no-cyclone dates, our results support instead that the SST is the dominating factor determining the distribution of specific humidity, with cyclones playing only a modulating role.

\subsubsection{Upper-level Wind Speed at $300 \mathrm{hPa}$}

In CNTL, the strongest climatological winds reach $40 \mathrm{~m} \mathrm{~s}^{-1}$ in the Gulf Stream region and occur in a southwest (SW) to northeast (NE) tilted band (Fig. 10a) that is located close to the position of the SST front (Fig. 3a). In the Kuroshio region, the climatological jet is more zonal than in the North Atlantic, exceeds $60 \mathrm{~m} \mathrm{~s}^{-1}$ (Fig. 10e), and is located somewhat to the south of the SST front (Fig. 3b). As for almost all the other fields, there is a good agreement between ERA-Interim and the AFES 

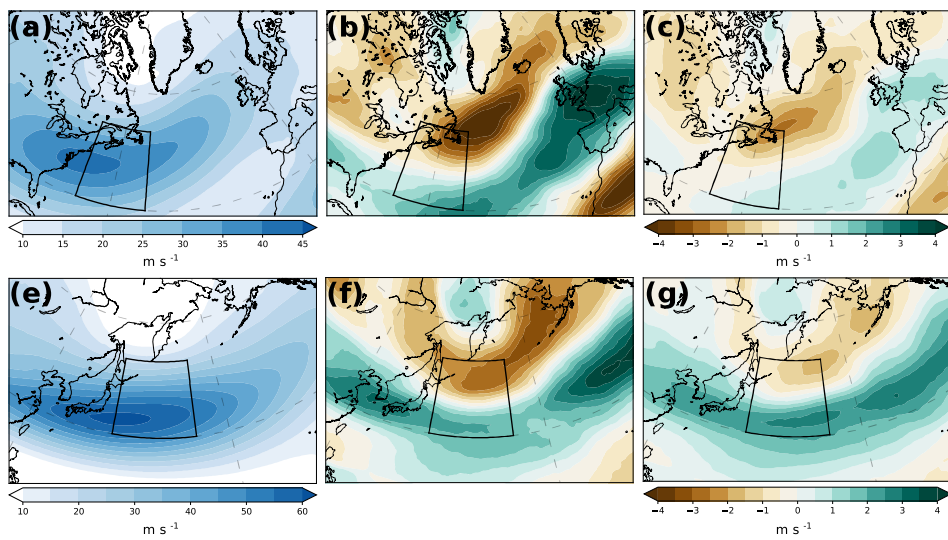
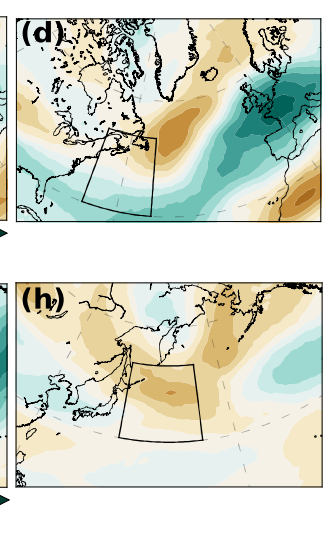

Figure 10. (a) Climatological wind speed at $300 \mathrm{hPa}$ (shading, $\mathrm{m} \mathrm{s}^{-1}$ ) for the North Atlantic for CNTL. (b) Difference of the wind speed climatology between SMTHG and CNTL. (c,d) As (b), but only considering the dates with (c) and without (d) cyclones being present in the Gulf Stream region. (e-h) As (a-d), but for the Kuroshio region. The Gulf Stream and Kuroshio regions are marked with a black box, respectively. Panels (c,d,g,h) are scaled such that their sum yields panels (b) and (f), respectively.

simulations, with a slightly reduced maximum wind speed in the Gulf Stream region (approx. $5 \mathrm{~m} \mathrm{~s}{ }^{-1}$ ) and the maximum wind speed being geographically less extended over the North Pacific in the AFES climatology compared to ERA-Interim (compare Fig. 10a,e and Fig. A2c,f).

In both basins, we observe decreasing (increasing) wind speeds to the north (south) of the climatological jet position after the SST smoothing (Fig. 10b,f). This dipole is more pronounced downstream, in the central and eastern North Atlantic and Pacific, respectively. Kuwano-Yoshida and Minobe (2017) documented a similar difference pattern for the North Pacific jet.

The presence (Fig. 10c) or absence (Fig. 10d) of cyclones in the Gulf Stream region does not have a considerable imprint on the distribution of the observed upper-level wind speed differences, with dates with cyclones present accounting for less of the climatological wind differences. In the Pacific, however, the contribution from cyclones determines the overall dipolar structure of the wind speed differences (Fig. 10f-h). In contrast, in the absence of cyclones, wind speeds are reduced throughout the Kuroshio region as well as in most parts of the North Pacific (Fig. 10h).

This discrepancy between the contributions of cyclones in the North Atlantic versus North Pacific response to the smoothed SSTs might arise from the different relative shifts of cyclones and jets in these sectors (Fig. 4). Whereas cyclones and jets shift southward in tandem in the North Atlantic, it is mainly the cyclones that shift southward in the North Pacific, while the North Pacific jet intensifies in-place. Thus, the smoothed SSTs in the Kuroshio region allow cyclones to propagate closer to the 
climatological position of the Pacific jet, thereby intensifying its eddy-driven component, while reducing the occurrence of a separate eddy-driven jet further north. This interpretation explains both the observed focusing and strengthening of the Pacific jet (Figs. 4d, 10f), and the larger contribution of cyclones to the upper-level response to the smoothed SSTs (Fig. 10g,h).

\section{Conclusions}

We quantified and attributed differences in the atmospheric response when using realistic (CNTL) and smooth SSTs for the North Atlantic (SMTHG) and North Pacific (SMTHK), respectively, based on simulations with the AFES 3 model. The CNTL simulation compares well to ERA-Interim, except for considerably larger latent heat fluxes in CNTL, but these are most likely associated with the lower SST resolution in ERA-Interim prior to 2002. Given the stronger SST gradient in the Atlantic, the effect of the smoothing on the SST front yields stronger SST differences between CNTL and the respective smooth experiments (see Fig. 1c,f) as well as a distinctly stronger reduction of the SST gradient in the Atlantic compared to the Pacific (see Fig. $2 \mathrm{c}, \mathrm{f})$.

415 We first examined the impact of the smoothing of the SST on the intensification of individual cyclones. Considering only cyclones with a maximum intensification in the Gulf Stream or the Kuroshio region, we classified them into 3 categories based on their propagation relative to the SST front, where cyclones either always stay on the cold (C1) or warm (C2) side of the SST front or they cross the SST front from the warmer to the colder side (C3). Similar deepening rates for all these cyclonecategories across all experiments reveal the rather minor role of the SST gradient on the intensification of individual cyclones. This result is valid for both ocean basins, though it is particularly relevant for the Gulf Stream region where the SST smoothing dramatically weakens the strong SST gradient.

Considering all cyclones propagating in either the North Atlantic or the North Pacific, we found the cyclone density in the storm track to decrease when the SSTs are smoothed in the Kuroshio and even more so in the Gulf Stream region. We relate the different response of the cyclone densities for the two regions to the more pronounced reduction of the SST gradient in SMTHG for the Atlantic compared to SMTHK for the Pacific. Overall, we observe an equator-ward shift in cyclone density in both regions, which is more pronounced over the central and eastern ocean basins. Both cyclone density differences have a distinct SW-NE tilt, basically following the storm track. An analogous southward shift is observed in the upper-level jet for the North Atlantic, whereas for the North Pacific such a shift is absent and the difference between the experiments instead reveals a more meridionally focused and zonally extended jet for smoother SST.

430 We found a considerable decrease of both latent and sensible heat fluxes along the SST front when smoothing the SSTs, which was more pronounced across the SST front in the Gulf Stream region compared to the Kuroshio. Analogous to the surface heat fluxes, precipitation in the Gulf Stream region is strongly reduced when smoothing the SST front, which is particularly evident for convective precipitation on the warm side of the Gulf Stream SST front. However, both types of precipitation are only slightly affected by the SST smoothing in the Kuroshio region. Differences in specific humidity at $850 \mathrm{hPa}$ feature 
related to the smaller differences in the SST and SST front between CNTL and the smoothed fields in the Pacific compared the Atlantic.

To clarify whether the differences between the realistic and smooth experiments stem directly from differences in the SST or from the occurrence of cyclones, we subdivided the winter climatology into days with and without cyclones present in the Gulf Stream or Kuroshio region. We found the contribution from time-steps without cyclones in the Gulf Stream or Kuroshio region to more closely resemble the climatological differences in surface heat fluxes. Differences in precipitation, however, were more closely associated with cyclones being present in the Gulf Stream or Kuroshio region.

Differences in specific humidity in the Gulf Stream region between CNTL and SMTHG are mainly attributable to days when cyclones are not present in the region. For the Kuroshio, however, the differences are almost equally attributed between timesteps with and without cyclones present in the region. Likewise, while cyclones in the Gulf Stream region do not seem to have a considerable imprint on the differences in the upper-level wind, differences in the Kuroshio region are mainly attributable to time-steps when cyclones are present. We associate this discrepancy between the two basins to cyclones in the Pacific propagating more closely to the climatological jet position in SMTHK, thereby intensifying its eddy-driven component.

Overall, our analysis highlights that SST fronts only have a minor impact on the characteristics and intensification of individual cyclones propagating in the Gulf Stream or Kuroshio region. Nevertheless, we found a large-scale response with decreased cyclone density as well as an equator-ward shift of cyclone densities associated with the SST smoothing. Analogously, the upper-level jet shifts equator-ward in the North Atlantic, while the Pacific jet strengthens and extends more zonally eastward along its climatological location, which can be associated with the more collocated storm track. The effect of the SST smoothing was stronger in the Gulf Stream region, where the smoothing has a larger impact on the climatologically sharper SST front. Subdividing time-steps into those with and without cyclones in the two regions underlined the leading role of the SST to explain the differences in the heat fluxes, specific humidity, and convective precipitation, with cyclones generally playing a secondary modulating role.

Code availability. The codes to construct the figures in this study is available upon request.

Data availability. ERA-Interim data are provided by European Centre for Medium-Range Weather Forecasts (ECMWF) available online at 

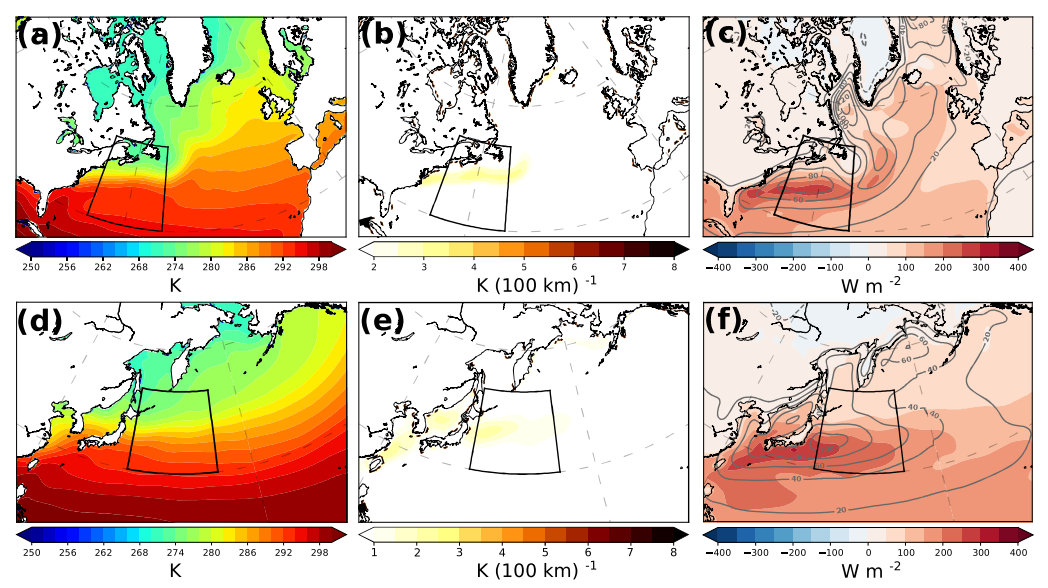

Figure A1. (a) DJF climatology over ERA-Interim period $1982-2000$ for (a) the SSTs (K), (b) the SST gradient (K (100 km) $\left.{ }^{-1}\right)$, (c) the latent (shading, $\mathrm{W} \mathrm{m}^{-2}$ ) and sensible heat fluxes (contours, $\mathrm{W} \mathrm{m}^{-2}$ ) for the North Atlantic. (d-f) As (a-c), but for the North Pacific. The Gulf Stream and Kuroshio regions are marked with a black box, respectively.

Acknowledgements. We thank ECMWF for providing the ERA-Interim data and Akira Kuwano-Yoshida and Akira Yamazaki, who provided the AFES 3 data. The AFES 3 data was supported by the Grant-in-Aid for Scientific Research on Innovative Areas 22106008 ("A 'hot spot' in the climate system: Extra-tropical air-sea interaction under the East Asian monsoon system") from the Ministry of Education, Culture, Sports, Science, and Technology of Japan, and calculated using the Earth Simulator under JAMSTEC support. 

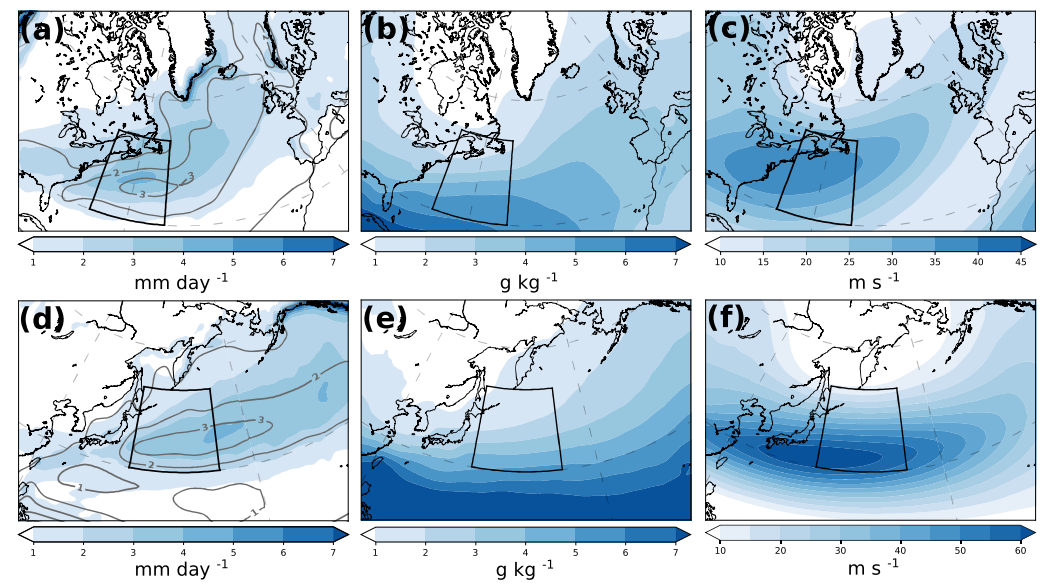

Figure A2. (a) DJF climatology over ERA-Interim period 1982-2000 for (a) the large-scale precipitation (shading, mm day ${ }^{-1}$ ) and the convective precipitation (contours, $\mathrm{mm} \mathrm{day}^{-1}$ ), (b), the specific humidity at $850 \mathrm{hPa}\left(\mathrm{g} \mathrm{kg}^{-1}\right.$ ) and (c) the wind speed at $300 \mathrm{hPa}\left(\mathrm{m} \mathrm{s}^{-1}\right)$ for the North Atlantic. (d-f) As (a-c), but for the North Pacific. The Gulf Stream and Kuroshio regions are marked with a black box, respectively.

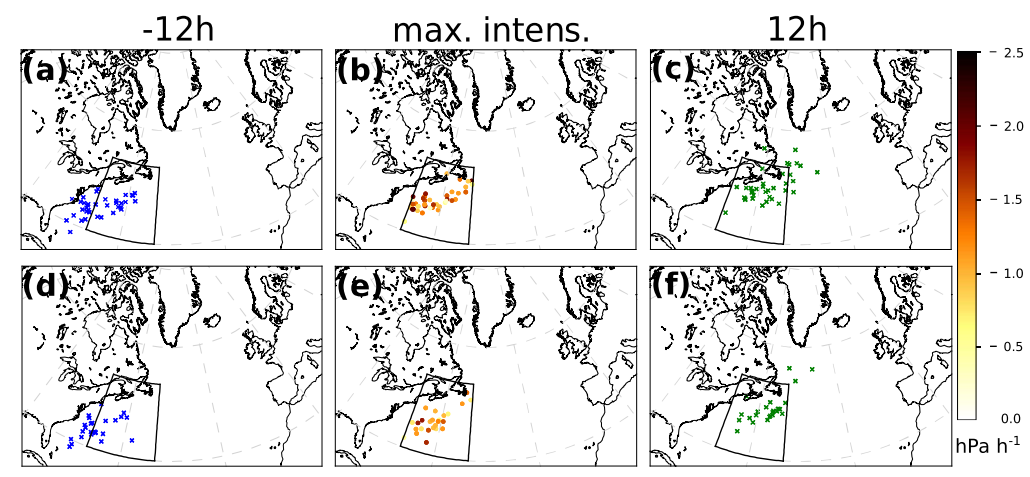

Figure A3. Locations of cyclones for $\mathrm{C} 3$ in the North Atlantic, (a) 12 hours prior to maximum intensification (blue crosses), (b) at the time of maximum intensification (dots colored depending on their pressure tendency, $\left(\mathrm{hPa} \mathrm{h}^{-1}\right)$ ) and (c) 12 hours past maximum intensification (green crosses) in the CNTL experiment. (d-f) As (a-c), but for the SMTHG experiment. The Gulf Stream region is marked with a black box. 
https://doi.org/10.5194/wcd-2020-50

Preprint. Discussion started: 12 October 2020

(c) Author(s) 2020. CC BY 4.0 License.

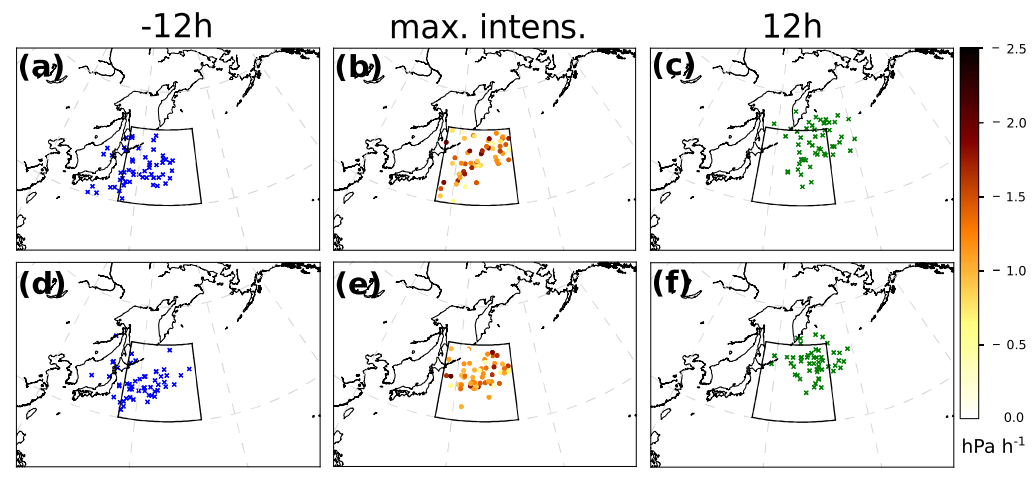

Figure A4. Locations of cyclones for $\mathrm{C} 3$ in the North Pacific, (a) 12 hours prior to maximum intensification (blue crosses), (b) at the time of maximum intensification (dots colored depending on their pressure tendency, $\left(\mathrm{hPa} \mathrm{h}^{-1}\right)$ ) and (c) 12 hours past maximum intensification (green crosses) in the CNTL experiment. (d-f) As (a-c), but for the SMTHK experiment. The Kuroshio region is marked with a black box. 


\section{References}

Alexander, M. A. and Scott, J. D.: Surface flux variability over the North Pacific and North Atlantic oceans, Journal of climate, 10, 2963$2978,1997$.

Berry, G., Reeder, M. J., and Jakob, C.: A global climatology of atmospheric fronts, Geophys. Res. Lett., 38, L04809, https://doi.org/10.1029/2010GL046451, 2011.

Bjerknes, J.: Life cycle of cyclones and the polar front theory of atmospheric circulation, Geophys. Publik., 3, 1-18, 1922.

Booth, J. F., Thompson, L., Patoux, J., and Kelly, K. A.: Sensitivity of Midlatitude Storm Intensification to Perturbations in the Sea Surface Temperature near the Gulf Stream, Mon. Wea. Rev., 140, 1241-1256, https://doi.org/10.1175/MWR-D-11-00195.1, 2012.

Brayshaw, D. J., Hoskins, B., and Blackburn, M.: The basic ingredients of the North Atlantic storm track. Part I: Land-sea contrast and orography., J. Atmos. Sci., 66, 2539-2558, https://doi.org/10.1175/2009JAS3078.1, 2009.

Chang, E. K. and Song, S.: The seasonal cycles in the distribution of precipitation around cyclones in the western North Pacific and Atlantic, Journal of the atmospheric sciences, 63, 815-839, 2006.

Chen, G., Plumb, R. A., and Lu, J.: Sensitivities of zonal mean atmospheric circulation to SST warming in an aqua-planet model, Geophysical Research Letters, 37, 2010.

Dacre, H. F., Josey, S. A., and Grant, A. L.: Extratropical cyclone induced sea surface temperature anomalies in the 2013/14 winter, Weather Clim. Dyn., 1, 27-44, https://doi.org/10.5194/wcd-1-27-2020, 2020.

de Vries, H., Scher, S., Haarsma, R., Drijfhout, S., and Van Delden, A.: How Gulf-Stream SST-fronts influence Atlantic winter storms, Climate Dyn., 52, 5899-5909, https://doi.org/10.1007/s00382-018-4486-7, 2019.

Dee, D. P., Uppala, S. M., Simmons, A. J., Berrisford, P., Poli, P., Kobayashi, S., Andrae, U., Balmaseda, M. A., Balsamo, G., Bauer, P., Bechtold, P., Beljaars, A. C. M., van de Bergd, L., Bidlot, J., Bormann, N., Delsol, C., Dragani, R., Fuentes, M., Geer, A. J., Haimberger, L., Healy, S. B., Hersbach, H., Holm, E. V., Isaksen, L., Kållberg, P., M. Köhler, M. M., McNally, A. P., Monge-Sanz, B. M., Morcrette, J.-J., Park, B.-K., Peubey, C., de Rosnay, P., Tavolato, C., Thepaut, J.-N., and Vitart, F.: The ERA-Interim reanalysis: configuration and performance of the data assimilation system, Quart. J. Roy. Meteor. Soc., 137, 553-587, https://doi.org/10.1002/qj.828, 2011.

Enomoto, T., Kuwano-Yoshida, A., Komori, N., and Ohfuchi, W.: Description of AFES 2: Improvements for high-resolution and coupled simulations, in: High Resolution Numerical Modelling of the Atmosphere and Ocean, pp. 77-97, Springer, 2008.

Evans, M. S., Keyser, D., Bosart, L. F., and Lackmann, G. M.: A satellite-derived classification scheme for rapid maritime cyclogenesis, Monthly weather review, 122, 1381-1416, 1994.

Hawcroft, M., Shaffrey, L., Hodges, K., and Dacre, H.: How much Northern Hemisphere precipitation is associated with extratropical cyclones?, Geophysical Research Letters, 39, https://doi.org/10.1029/2012GL053866, 2012.

Holton, J. R. and Hakim, G. J.: An Introduction to Dynamic Meteorology, Academic Press, 2012.

Hoskins, B. J. and Hodges, K. I.: New perspectives on the Northern Hemisphere winter storm tracks, J. Atmos. Sci., 59, 1041-1061, https://doi.org/10.1175/1520-0469(2002)059<1041:NPOTNH>2.0.CO;2, 2002.

Hoskins, B. J. and Valdes, P. J.: On the existence of storm-tracks, Journal of the atmospheric sciences, 47, 1854-1864, 1990.

Hotta, D. and Nakamura, H.: On the significance of sensible heat supply from the ocean in the maintenance of mean baroclinicity along storm tracks, J. Climate, 24, 3377-3401, https://doi.org/10.1175/2010JCLI3910.1, 2011.

Jacobs, N., Raman, S., Lackmann, G., and Childs Jr, P.: The influence of the Gulf Stream induced SST gradients on the US East Coast winter 
Jenkner, J., Sprenger, M., Schwenk, I., Schwierz, C., Dierer, S., and Leuenberger, D.: Detection and climatology of fronts in a high-resolution model reanalysis over the Alps, Meteorol. Appl., 17, 1-18, https://doi.org/10.1002/met.142, 2010.

Joyce, T. M., Kwon, Y.-O., and Yu, L.: On the relationship between synoptic wintertime atmospheric variability and path shifts in the Gulf Stream and the Kuroshio Extension, Journal of Climate, 22, 3177-3192, 2009.

510 Kuwano-Yoshida, A. and Minobe, S.: Storm-track response to SST fronts in the northwestern Pacific region in an AGCM, Journal of Climate, 30, 1081-1102, 2017.

Kuwano-Yoshida, A., Enomoto, T., and Ohfuchi, W.: An improved PDF cloud scheme for climate simulations, Quarterly Journal of the Royal Meteorological Society, 136, 1583-1597, 2010a.

Kuwano-Yoshida, A., Minobe, S., and Xie, S.-P.: Precipitation response to the Gulf Stream in an atmospheric GCM, Journal of Climate, 23, $515 \quad 3676-3698,2010$ b.

Ma, X., Chang, P., Saravanan, R., Montuoro, R., Hsieh, J.-S., Wu, D., Lin, X., Wu, L., and Jing, Z.: Distant influence of Kuroshio eddies on North Pacific weather patterns?, Scientific reports, 5, 17 785, 2015.

Ma, X., Chang, P., Saravanan, R., Montuoro, R., Nakamura, H., Wu, D., Lin, X., and Wu, L.: Importance of resolving Kuroshio front and eddy influence in simulating the North Pacific storm track, Journal of Climate, 30, 1861-1880, 2017.

520 Masunaga, R., Nakamura, H., Miyasaka, T., Nishii, K., and Tanimoto, Y.: Separation of climatological imprints of the Kuroshio Extension and Oyashio fronts on the wintertime atmospheric boundary layer: Their sensitivity to SST resolution prescribed for atmospheric reanalysis, Journal of Climate, 28, 1764-1787, 2015.

Meinen, C. S. and Luther, D. S.: Structure, transport, and vertical coherence of the Gulf Stream from the Straits of Florida to the Southeast Newfoundland Ridge, Deep-Sea Res. Pt. I, 112, 137-154, https://doi.org/10.1016/j.dsr.2016.03.002, 2016.

525 Michel, C., Terpstra, A., and Spengler, T.: Polar mesoscale cyclone climatology for the Nordic Seas based on ERA-Interim, J. Climate, 31, 2511-2532, https://doi.org/10.1175/JCLI-D-16-0890.1, 2018.

Minobe, S., Kuwano-Yoshida, A., Komori, N., Xie, S.-P., and Small, R. J.: Influence of the Gulf Stream on the troposphere, Nature, 452, 206-210, https://doi.org/10.1038/nature06690, 2008.

Murray, R. J. and Simmonds, I.: A numerical scheme for tracking cyclone centres from digital data. Part I: Development and operation of 530 the scheme, Aust. Met. Mag., 39, 155-166, 1991a.

Murray, R. J. and Simmonds, I.: A numerical scheme for tracking cyclone centres from digital data. Part II: application to January and July general circulation model simulations, Aust. Met. Mag., 39, 167-180, 1991 b.

Nakamura, H.: Midwinter suppression of baroclinic wave activity in the Pacific, Journal of the atmospheric sciences, 49, 1629-1642, 1992.

Nakamura, H., Sampe, T., Tanimoto, Y., and Shimpo, A.: Observed associations among storm tracks, jet streams and midlatitude oceanic 535 fronts, Geoph. Monog. Series, 147, 329-345, https://doi.org/10.1029/147GM18, 2004.

Nakamura, H., Sampe, T., Goto, A., Ohfuchi, W., and Xie, S.-P.: On the importance of midlatitude oceanic frontal zones for the mean state and dominant variability in the tropospheric circulation, Geophysical Research Letters, 35, 2008.

Newman, M., Kiladis, G. N., Weickmann, K. M., Ralph, F. M., and Sardeshmukh, P. D.: Relative contributions of synoptic and low-frequency eddies to time-mean atmospheric moisture transport, including the role of atmospheric rivers, Journal of climate, 25, 7341-7361, 2012.

540 Ogawa, F. and Spengler, T.: Prevailing Surface Wind Direction during Air-Sea Heat Exchange, J. Climate, 32, 5601-5617, https://doi.org/10.1175/JCLI-D-18-0752.1, 2019.

Ogawa, F., Nakamura, H., Nishii, K., Miyasaka, T., and Kuwano-Yoshida, A.: Dependence of the climatological axial latitudes of the tropospheric westerlies and storm tracks on the latitude of an extratropical oceanic front, Geophysical research letters, $39,2012$. 
Ohfuchi, W., Nakamura, H., Yoshioka, M. K., Enomoto, T., Takaya, K., Peng, X., Yamane, S., Nishimura, T., Kurihara, Y., Ninomiya, K., et al.: 10-km mesh meso-scale resolving simulations of the global atmosphere on the Earth Simulator: Preliminary outcomes of AFES (AGCM for the Earth Simulator), J. Earth Simulator, 1, 8-34, 2004.

O'Reilly, C. H., Minobe, S., Kuwano-Yoshida, A., and Woollings, T.: The Gulf Stream influence on wintertime North Atlantic jet variability, Quarterly Journal of the Royal Meteorological Society, 143, 173-183, 2017.

Papritz, L. and Spengler, T.: Analysis of the slope of isentropic surfaces and its tendencies over the North Atlantic, Quart. J. Roy. Meteor. Soc., 141, 3226-3238, https://doi.org/10.1002/qj.260, 2015.

Parfitt, R., Czaja, A., Minobe, S., and Kuwano-Yoshida, A.: The atmospheric frontal response to SST perturbations in the Gulf Stream region, Geophys. Res. Lett., 43, 2299-2306, https://doi.org/10.1002/2016GL067723, 2016.

Parfitt, R., Czaja, A., and Kwon, Y.-O.: The impact of SST resolution change in the ERA-Interim reanalysis on wintertime Gulf Stream frontal air-sea interaction, Geophysical Research Letters, 44, 3246-3254, 2017.

555 Peixoto, J. P. and Oort, A. H.: Physics of climate, 1992.

Pfahl, S. and Wernli, H.: Quantifying the relevance of cyclones for precipitation extremes, Journal of Climate, 25, 6770-6780, 2012.

Piazza, M., Terray, L., Boé, J., Maisonnave, E., and Sanchez-Gomez, E.: Influence of small-scale North Atlantic sea surface temperature patterns on the marine boundary layer and free troposphere: A study using the atmospheric ARPEGE model, Climate dynamics, 46, 1699-1717, 2016.

560 Reynolds, R. W., Smith, T. M., Liu, C., Chelton, D. B., Casey, K. S., and Schlax, M. G.: Daily high-resolution-blended analyses for sea surface temperature, Journal of Climate, 20, 5473-5496, 2007.

Riviere, G. and Joly, A.: Role of the low-frequency deformation field on the explosive growth of extratropical cyclones at the jet exit. Part II: Baroclinic critical region, Journal of the atmospheric sciences, 63, 1982-1995, 2006.

Rudeva, I. and Gulev, S. K.: Composite analysis of North Atlantic extratropical cyclones in NCEP-NCAR reanalysis data, Mon. Wea. Rev., 565 139, 1419-1446, https://doi.org/10.1175/2010MWR3294.1, 2011.

Ruprecht, E., Schröder, S. S., and Ubl, S.: On the relation between NAO and water vapour transport towards Europe, Meteorologische Zeitschrift, 11, 395-401, 2002.

Sampe, T., Nakamura, H., Goto, A., and Ohfuchi, W.: Significance of a midlatitude SST frontal zone in the formation of a storm track and an eddy-driven westerly jet, Journal of Climate, 23, 1793-1814, 2010.

570 Sanders, F.: Explosive cyclogenesis in the west-central North Atlantic Ocean, 1981-84. Part I: Composite structure and mean behavior, Mon. Wea. Rev., 114, 1781-1794, https://doi.org/10.1175/1520-0493(1986)114<1781:ECITWC>2.0.CO;2, 1986.

Sanders, F. and Gyakum, J. R.: Synoptic-dynamic climatology of the "bomb", Mon. Wea. Rev., 108, 1589-1606, https://doi.org/10.1175/1520-0493(1980)108<1589:SDCOT>2.0.CO;2, 1980.

Schemm, S., Rudeva, I., and Simmonds, I.: Extratropical fronts in the lower troposphere-global perspectives obtained from two automated methods, Quart. J. Roy. Meteor. Soc., 141, 1686-1698, https://doi.org/10.1002/qj.2471, 2015.

Schultz, D. M., Keyser, D., and Bosart, L. F.: The effect of large-scale flow on low-level frontal structure and evolution in midlatitude cyclones, Monthly weather review, 126, 1767-1791, 1998.

Sinclair, M. R. and Revell, M. J.: Classification and composite diagnosis of extratropical cyclogenesis events in the southwest Pacific, Mon. Wea. Rev., 128, 1089-1105, https://doi.org/10.1175/1520-0493(2000)128<1089:CACDOE>2.0.CO;2, 2000.

580 Small, R. J., Tomas, R. A., and Bryan, F. O.: Storm track response to ocean fronts in a global high-resolution climate model, Climate dynamics, 43, 805-828, 2014. 
Spensberger, C. and Spengler, T.: Feature-based Jet Variability in the Upper Troposphere, Journal of Climate, p. submitted, 2020.

Spensberger, C., Spengler, T., and Li, C.: Upper-tropospheric jet axis detection and application to the boreal winter 2013/14, Monthly Weather Review, 145, 2363-2374, 2017.

Tanimoto, Y., Nakamura, H., Kagimoto, T., and Yamane, S.: An active role of extratropical sea surface temperature anomalies in determining anomalous turbulent heat flux, Journal of Geophysical Research: Oceans, 108, 2003.

Tozuka, T., Ohishi, S., and Cronin, M. F.: A metric for surface heat flux effect on horizontal sea surface temperature gradients, Climate Dynamics, 51, 547-561, 2018.

Tsopouridis, L., Spensberger, C., and Spengler, T.: Characteristics of Cyclones Following Different Pathways in the Gulf Stream Region, Quarterly Journal of the Royal Meteorological Society;1-16, https://doi.org/10.1002/qj.3924, 2020a.

Tsopouridis, L., Spensberger, C., and Spengler, T.: Cyclone Intensification in the Kuroshio Region and its relation to the Sea Surface Temperature Front and Upper-Level Forcing, Quarterly Journal of the Royal Meteorological Society, https://doi.org/10.1002/qj.3929, 2020b.

Uccellini, L. W., Kocin, P. J., Petersen, R. A., Wash, C. H., and Brill, K. F.: The Presidents' Day cyclone of 18-19 February 1979: Synoptic overview and analysis of the subtropical jet streak influencing the pre-cyclogenetic period, Monthly weather review, 112, 31-55, 1984

595 Vanniere, B., Czaja, A., Dacre, H. F., and Woollings, T.: A "Cold Path" for the Gulf Stream-Troposphere Connection, J. Climate, 30, 1363-1379, https://doi.org/10.1175/JCLI-D-15-0749.1, 2017.

Wang, C.-C. and Rogers, J. C.: A composite study of explosive cyclogenesis in different sectors of the North Atlantic. Part I: Cyclone structure and evolution, Mon. Wea. Rev., 129, 1481-1499, https://doi.org/10.1175/1520-0493(2001)129<1481:ACSOEC>2.0.CO;2, 2001.

Wang, L., Hu, H., and Yang, X.: The atmospheric responses to the intensity variability of subtropical front in the wintertime North Pacific, $600 \quad$ Climate Dynamics, 52, 5623-5639, 2019.

Yao, Y., Zhong, Z., and Yang, X.-Q.: Impacts of the subarctic frontal zone on the North Pacific storm track in the cold season: an observational study, International Journal of Climatology, 38, 2554-2564, 2018.

Yoshida, A. and Asuma, Y.: Structures and environment of explosively developing extratropical cyclones in the northwestern Pacific region, Monthly Weather Review, 132, 1121-1142, 2004.

605 Zhang, C., Liu, H., Xie, J., Lin, P., Li, C., Yang, Q., and Song, J.: North Pacific storm track response to the mesoscale SST in a global high-resolution atmospheric model, Climate Dynamics, 55, 1597-1611, 2020.

Zolina, O. and Gulev, S. K.: Synoptic variability of ocean-atmosphere turbulent fluxes associated with atmospheric cyclones, Journal of climate, 16, 2717-2734, 2003. 